\title{
EFFECTS OF 6-WEEK NORDIC WALKING TRAINING ON BODY COMPOSITION AND ANTIOXIDANT STATUS FOR WOMEN > 55 YEARS OF AGE
}

\section{AGATA CEBULA ${ }^{1}$, ANNA KATARZYNA TYKA ${ }^{2}$, WANDA PILCH ${ }^{3}$, ZBIGNIEW SZYGUŁA ${ }^{4}$, TOMASZ PAŁKA ${ }^{3}$, KATARZYNA SZTAFA-CABAEA ${ }^{5}$, BARBARA FRĄCZEK ${ }^{4}$, and ALEKSANDER TYKA ${ }^{3}$}

${ }^{1}$ University of Physical Education, Kraków, Poland

Faculty of Physical Education and Sport, Department of Biological Regeneration and Posture Correction

${ }^{2}$ University of Physical Education, Kraków, Poland

Faculty of Tourism and Leisure, Department of Recreation and Biological Regeneration

${ }^{3}$ University of Physical Education, Kraków, Poland

Faculty of Physical Education and Sport, Department of Physiology and Biochemistry

${ }^{4}$ University of Physical Education, Kraków, Poland

Faculty of Physical Education and Sport, Department of Sport Medicine and Nutrition

${ }^{5}$ State Higher Vocational School in Nowy Sącz, Nowy Sącz, Poland

Institute of Physical Culture

\begin{abstract}
Objectives: This study examined the effects of 6-week Nordic walking (NW) workout with individually customized intensity, on the body composition, and oxidative stress biomarkers for women $>55$ years of age. Material and Methods: Sixteen sedentary women (age 58.1 \pm 2.02 years old, body mass index (BMI) $26.74 \pm 2.72 \mathrm{~kg} / \mathrm{m}^{2}$ ) worked out the NW 3 times/week over the 6-week period. Training intensity, which reflected the dominance of oxygen metabolism, was determined based on changes in physiological indicators during graded exercise on a treadmill (walking with poles). The body composition and oxidative stress biomarkers in blood were measured before and after the exercise routine. Results: After the training period, body weight, body fat percentage, body mass index and uric acid levels in serum decreased significantly $(\mathrm{p}<0.05)$. At the same time the plasma total antioxidant status increased considerably $(\mathrm{p}<0.05)$, while the total oxidative status and the oxidized low-density lipoproteins concentration levels did not change significantly $(\mathrm{p}>0.05)$. Conclusions: Within a relatively short time, the Nordic walking with the customized intensity level focused on the dominance of fat metabolism, decreased body fat and improved the blood antioxidant defense system for previously sedentary women. Int J Occup Med Environ Health 2017;30(3):445-454
\end{abstract}

Key words:

Oxidative stress, Women, Antioxidants, Body composition, Health training, Nordic walking

Funding: grant "Influence of the Nordic Walking training on body composition, energy expenditure, physical capacity, lipid profile and haematological indices in women over 55 years of age" for young scientists No. 12/MN/IFC/2011 awarded by the Polish Ministry of Science and Higher Education. Grant manager: Agata Cebula, Ph.D. Received: November 26, 2015. Accepted: April 26, 2016.

Corresponding author: A. Cebula, University of Physical Education, Faculty of Physical Education and Sport, Department of Biological Regeneration and Posture Correction, al. Jana Pawła II 78, 31-571 Kraków, Poland (e-mail: agata.cebula@awf.krakow.pl). 


\section{INTRODUCTION}

Regular physical activity helps to alleviate age-related involutional changes which occur in human body, it prevents the negative effects of hypokinesia [1], and slows down decline in maximal aerobic capacity [2]. It is also well known that physical exercise helps in reducing body weight and body fat [3], which tend to increase with age [4,5].

Consistent physical activity plays an important part in improving the protection of the body against harmful effects of oxidation processes [6]. It has been proven that aerobic workout may reduce the levels of oxidative stress markers and improve the antioxidant defense system in blood $[7,8]$. These changes probably manifest the body's adaptation to repeated oxidative stress induced by exercise, which activates moderate production of reactive oxygen species (ROS) and reactive nitrogen species (RNS) in contracting skeletal muscles [9], and may stimulate adaptive increase in antioxidants as well as improvement of deoxyribonucleic acid (DNA) repair processes. As a result the cellular resistance to oxidative damages increases, which may contribute to delaying the aging process and decreasing the occurrence of diseases associated with oxidative stress [10,11].

The Nordic walking (NW) has recently become a popular form of physical activity, especially among the population of older people. It has been proven that walking with poles engages the upper parts of the body to a larger extent than a regular march [12], therefore seems to be a stronger training stimulus for the body.

Despite the growing interest of researchers in this form of physical activity, the impact of regular walking with sticks on aging body is still scantily documented in the literature. In particular, the response of body's antioxidant mechanisms to this exercise is unclear. Therefore the key objective of this study has been to determine the impact of the 6-week NW exercise routine with individualized intensity level, focused on the dominance of fat metabolism, on the indicators of body composition and concentration of oxidative stress markers in the blood, for women $>55$ years of age. Instead of previously used observation techniques, in which the intensity of exercises during the NW workouts was traditionally determined by using objective (heart rate - HR, percent of maximal heart rate $-\% \mathrm{HR}_{\max }$, metabolic equivalent of task - MET) [13-15] or subjective methods (e.g., based on subjective perception of exertion or walking speed) [16-18], a nonstandard, precise method of determining and controlling the intensity of exercise was selected in order to achieve the domination of fat metabolism during exercise. Currently, there is no data available regarding the effects of the Nordic walking training with such intensity level on women's health.

\section{MATERIAL AND METHODS \\ Selection of the subjects}

The study involved 16 women in the 56-62 age range, selected from the group of volunteers willing to participate in the research. The sample size was selected taking into account the strict monitoring of the training process using specialized measuring equipment and supervision of each training session by specialists.

The eligibility criteria included no medical contraindications to undergo stress test, good overall health (no diagnosed cardiovascular, pulmonary, metabolic, neurological and oncological diseases), post-menopause, nonsmoking and non-drinking status (at least 4 weeks prior to the study), no previous experience of walking with poles or regular walking for exercise and a low level of physical activity according to the International Physical Activity Questionnaire (IPAQ) - Polish short version [19].

The individuals, who took medication or supplements with vitamins and mineral compounds which could affect the total antioxidant status (TAS) or the other variables, were excluded from participation. The subjects were instructed not to change their usual diet nor alter their physical activity habits during the study. 


\section{Ethics}

All participants provided a written consent to take part in the study. The research project obtained the approval of the Bioethics Commission for Scientific Research at the Regional Medical Chamber in Kraków, Poland (No. 83/KBL/OIL/2011).

\section{Experimental procedure and protocols}

The research schedule included a pilot study, which was meant to familiarize the participants with the testing procedure, and 2 series of identical main tests, the first one carried out before the start of the exercise routine and the second one - on the 3rd day after its completion (to minimize acute effects of exercise). The main tests methodology was carried out in 2 stages. In the 1st stage the levels of anthropometric and body composition indicators were determined and blood samples were collected for biochemical analysis. In the 2nd stage the women, after learning the proper Nordic walking technique, performed exercise with gradually increasing intensity (graded exercise - GE) on a treadmill, consisting of walking with poles (the Nordic walking graded exercise - $\mathrm{NW}_{\mathrm{GE}}$ ), during which the cardiorespiratory fitness indicators were recorded. Values for the physiological indicators, including the energy expenditure, were used for determining individual exercise intensity for each woman.

\section{Training description and monitoring}

After completion of the baseline tests, all participants started the series of 18 workout sessions. The 90-min sessions 3 times a week were conducted by a certified instructor for 6 weeks in the morning hours (not sooner than $2 \mathrm{~h}$ after a light meal). Each workout session consisted of a warm-up activity (15 min), a walk with poles on a flat grassy path with individually customized intensity level (60 min) and a cool-down phase (15 min) which included relaxing and stretching exercises.
The exercise intensity selection for the workouts was geared at the maximum rates of mobilization of fat reserves. Efficient use of energy sources which consist of free fatty acids (FFA) was attempted by determining exercise intensity based on the level of selected physiological parameters recorded in the graded exercise on a treadmill $\left(\mathrm{NW}_{\mathrm{GE}}\right)$.

The optimal walk intensity was determined individually for each person (based on the changes in the respiratory exchange indicators, such as the fraction of oxygen in the expired air $\left(\mathrm{FEO}_{2}\right)$, the respiratory exchanged ratio (RER) and minute oxygen uptake $\left(\mathrm{VO}_{2}\right)$ ) at the level, at which the oxygen use by the body was the highest [20], and the RER values fluctuated between 0.7 and 0.78 . Such intensity of walk with poles, mainly engaged aerobic metabolism of free fatty acids. Accordingly, in this range of the RER values, the participation of fat metabolism in energy release was $73.7-100 \%$ [21].

The pulse rates registered at such intensity of exercise allowed relatively precise determination of individual HR training range. During the walk, the subjects maintained the due heart rate $(\mathrm{HR} \pm 4$ beats/min) previously set in the laboratory, which was monitored with the use of telemetry. During 3 selected sessions (in 1st, 4th and 6th week), $30 \mathrm{~min}$ into the main workout, respiratory exchange indicators $\left(\mathrm{VO}_{2}, \mathrm{FEO}_{2}, \mathrm{RER}\right)$ were recorded with a portable ergospirometric device (Start 2000M, MES, Poland). This enabled the control of the energy expenditure during the exercise and, if necessary, modification of the individual physical load previously determined in the laboratory.

\section{Anthropometric measurements}

The body height (BH) was measured with the Martin anthropometer (GMP, Switzerland) to the nearest $0.1 \mathrm{~cm}$. The body mass (BM), lean body mass (LBM) and the percentage of body fat $(\mathrm{PF})$ were measured/estimated using the bioelectrical impedance analysis (BIA) via tetra-polar method using 8 touch electrodes (IOI - 353, Jawon Medical, Korea). It was made clear that $12 \mathrm{~h}$ before the tests the examined 
women should not perform any additional physical activities. The body mass index (BMI) was calculated by dividing the body weight $(\mathrm{kg})$ by the squared height $(\mathrm{m})$.

\section{Physiological parameters measurements}

Graded exercise $\left(\mathrm{NW}_{\mathrm{GE}}\right)$ was performed on $\mathrm{h} / \mathrm{p} /$ cosmos saturn 250/100R treadmill (h/p/cosmos, Germany) not sooner than $2 \mathrm{~h}$ after a light meal. It began with a $3 \mathrm{~min}$ warm-up at an initial walking speed of $1 \mathrm{~m} / \mathrm{s}$, which was then increased by $0.25 \mathrm{~m} / \mathrm{s}$ every $3 \mathrm{~min}$. The exercise lasted no longer than till the 5th load segment, i.e., the walking speed of $2 \mathrm{~m} / \mathrm{s}$. During the exercise the heart rate (HR) was recorded continuously, and the respiratory exchange indicators were measured every $30 \mathrm{~s}$ by means of the Start 2000M ergospirometric device (MES, Poland). The HR was recorded by means of Polar $610 \mathrm{~S}$ and Polar Team2 (Polar Electro, Finland).

\section{Biochemical analyses}

Blood samples were taken 3 days before the 1st training session and 3 days after the last training session, after overnight fasting, from the vein located in the cubital fossa, after 30-min rest in sitting position. Immundiagnostik AG (Germany) colorimetric test was used for assessing the determination of total antioxidant status (TAS) (sensitivity $130 \mu \mathrm{mol} / \mathrm{l})(\mathrm{ImAnOx}, \mathrm{KC} 5200)$ and total oxidant status (TOS) (sensitivity $7 \mu \mathrm{mol} / \mathrm{l}$ ) (PerOx, KC 5100) in plasma, while the immunoenzymatic method (enzyme-linked immunosorbent assay - ELISA) (sensitivity $4.130 \mathrm{ng} / \mathrm{ml}$ ) (ox-LDL, K 7810) was used for determining concentration of oxidized low-density lipoproteins (ox-LDL). The ElizaMAT 3000 Microtiterplate Reader (DRG International, Inc, USA) was used for assessing TAS, TOS and ox-LDL.

The concentration of uric acid (UA) in serum was measured by the ARCHITECT ci8200 analyser (Abbott, USA) using the enzymatic colorimetric method (Uric Acid test, Abbott, USA).
The values of biochemical indices after the course of workouts were corrected by changes in plasma volume $(\% \Delta \mathrm{PV})$ using the formula suggested by Kraemer and Brown [22]. To calculate the $\% \Delta \mathrm{PV}$ the formula proposed by Dill and Costill [23] was used with Harrison et al.'s modification [24]. For this purpose, before and after the course of workouts, the hemoglobin $(\mathrm{Hb})$ concentration in the whole blood was measured by means of Drabkin's method, and the hematocrit (Hct) value was assessed by means of the microhematocrit method.

The blood samples were stored at temperatures $<-70^{\circ} \mathrm{C}$ until assayed.

\section{Statistical analyses}

The statistical analysis was performed by means of the Statistica 10 software for Windows (StatSoft). The results were presented as the mean $(\mathrm{M}) \pm$ standard deviation (SD) and $95 \%$ confidence intervals (CI). Changes $(\Delta)$ in indicator levels resulting from the workout with the assumptions of distribution normality were analyzed using the Student's t-tests for related samples [25].

The level of $p<0.05$ was considered as statistically significant.

\section{RESULTS}

The average age of the women was $58.1 \pm 2.02$ years old and their mean height was $160.3 \pm 5.03 \mathrm{~cm}$. Participants had a mean BMI of $26.7 \pm 2.72 \mathrm{~kg} / \mathrm{m}^{2}$. According to the World Health Organization (WHO) these values indicate overweight (pre-obesity) [26]. The high body fat percentage in the total body weight ( $\mathrm{PF}>32 \%$ ) indicated its excess [27] (Table 1).

After the 6-week exercise routine the body mass (BM) decreased significantly by an average of $0.72 \pm 0.75 \mathrm{~kg}$ and the body fat percentage (PF) decreased by $0.43 \pm 0.53 \%$. The average BMI value decreased significantly by $0.29 \pm 0.29 \mathrm{~kg} / \mathrm{m}^{2}$ (Table 1), while the LBM did not change significantly. 
Table 1. Effects of 6-week Nordic walking (NW) for 16 women $>55$ years of age - body composition indicators, and oxidative stress biomarkers concentration before and after training period

\begin{tabular}{|c|c|c|c|c|}
\hline \multirow[t]{2}{*}{ Variable } & \multicolumn{2}{|c|}{$\begin{array}{l}\text { Parameters of respondents } \\
(\mathrm{M} \pm \mathrm{SD})\end{array}$} & \multirow[t]{2}{*}{$95 \% \mathrm{CI}$} & \multirow[t]{2}{*}{$\mathrm{p}$} \\
\hline & before NW & after NW & & \\
\hline Body mass $(\mathrm{BM})[\mathrm{kg}]$ & $68.84 \pm 8.62$ & $68.11 \pm 8.42$ & $0.33-1.12$ & 0.002 \\
\hline Body mass index (BMI) $\left[\mathrm{kg} / \mathrm{m}^{2}\right]$ & $26.74 \pm 2.72$ & $26.44 \pm 2.69$ & $0.14-0.45$ & 0.001 \\
\hline Body fat (PF) [\%] & $34.66 \pm 3.19$ & $34.23 \pm 3.15$ & $0.41-0.71$ & 0.006 \\
\hline Lean body mass $(\mathrm{LBM})[\mathrm{kg}]$ & $44.79 \pm 4.41$ & $44.61 \pm 4.35$ & $-0.18-0.54$ & 0.299 \\
\hline Total antioxidant status (TAS) $[\mu \mathrm{mol} / 1]$ & $314.10 \pm 40.32$ & $353.70 \pm 45.36$ & $-65.34-(-13.86)$ & 0.005 \\
\hline Total oxidant status (TOS) $[\mu \mathrm{mol} / \mathrm{l}]$ & $292.66 \pm 141.57$ & $330.92 \pm 145.95$ & $-104.58-28.07$ & 0.238 \\
\hline Uric acid (UA) $[\mu \mathrm{mol} / \mathrm{l}]$ & $285.46 \pm 55.88$ & $261.39 \pm 49.50$ & $4.28-43.85$ & 0.020 \\
\hline Oxidized low-density lipoprotein (ox-LDL) [ng/ml] & $79.99 \pm 54.18$ & $74.57 \pm 42.38$ & $-10.36-21.20$ & 0.475 \\
\hline
\end{tabular}

M - mean; SD - standard deviation; CI - confidence interval.

Table 2. Effects of 6-week Nordic walking (NW) for 16 women $>55$ years of age - changes in hematological indices and plasma volume after the training period

\begin{tabular}{|c|c|c|}
\hline \multirow[t]{2}{*}{ Variable } & \multicolumn{2}{|c|}{$\begin{array}{l}\text { Parameters of respondents } \\
\qquad \begin{array}{c}(\mathrm{N}=16) \\
(\mathrm{M} \pm \mathrm{SD})\end{array}\end{array}$} \\
\hline & before NW & after NW \\
\hline Hematocrit (Hct) [\%] & $40.16 \pm 2.69$ & $40.49 \pm 2.24$ \\
\hline Haemoglobin $(\mathrm{Hb})[\mathrm{g} / \mathrm{dl}]$ & $13.63 \pm 0.94$ & $13.49 \pm 1.00$ \\
\hline Changes in plasma volume $(\% \Delta \mathrm{PV})[\%]$ & - & $0.67 \pm 4.38$ \\
\hline
\end{tabular}

$\mathrm{M}$ - mean; SD - standard deviation.

After the series of workouts a significant increase in the total antioxidant status (TAS) in plasma was reported by $39.6 \pm 48.3 \mu \mathrm{mol} / \mathrm{l}$. However, no significant changes in the concentration of lipid peroxidation products (TOS) in plasma were noted. In the initial measurements, the average concentration of the UA was within the reference values (range: 180-420 $\mu \mathrm{mol} / \mathrm{l}$ ) [28], and after the exercise routine it dropped in the statistically significant way $(\Delta=-24.07 \pm 37.13 \mu \mathrm{mol} / \mathrm{l})$. The concentration of oxidized low-density lipoproteins (ox-LDL) in plasma did not change significantly (Table 1 ).

The values of biochemical indices after the training period were corrected by the changes in the plasma volume (Table 2).

\section{DISCUSSION}

The exercise routine that the women were subjected to resulted in a modest, yet statistically significant decrease in body weight, BMI, and percentage of body fat. This is in line with the previous reports which signaled that regular walking exercise with poles (during 8-13 weeks) could result in reduced body weight and fat deposits in previously sedentary middle-aged women [13-18].

It needs to be emphasized, however, that in our study a significant loss of body weight and fat percentage was noticed as early as 6 weeks into the exercise routine, which could result from the aptly customized exercise intensity. Considering that aging is associated with a progressive increase in fat mass [29], emphasis was put on the intensification 
of fat metabolism during exercise. It was taken into account that during exercise the highest level of fat oxidation falls between the intensity of $45 \%$ and $65 \%$ of maximal oxygen uptake $\left(\mathrm{VO}_{2 \max }\right)$, yet the specific $\mathrm{VO}_{2 \max }$ percentage at which it is achieved shows interindividual variation, also determined by sex, diet and fitness level [30,31]. Therefore, the exercise intensity at trainings was individually determined based on the measurement of changes in respiratory parameters $\left(\mathrm{FEO}_{2}, \mathrm{RER}, \mathrm{VO}_{2}\right)$ and heart rate (HR) in the graded exercise.

It was assumed that the exercise intensity played a significant role in the workout routine for elderly people, and the physical strain should be characterized by intensity at which the oxygen consumption by the body is the highest, and the respiratory exchange ratio (RER) remains within the range corresponding to the dominance of fat energy metabolism.

As the type of exercises at a given intensity determines the amount of fat burnt [30], the above physiological indices were evaluated during treadmill walking with poles. Since the NW on treadmill does not reflect reliably the same physical effort in the field [32] in selected walking sessions, the same physiological indices were controlled and recorded by means of a portable ergospirometric device. Any possible differences in results were the basis for verification of the initially determined HR exercise ranges. Such meticulous selection of intensity, according to the authors, was a strong point of the approach used for this exercise routine purposes. Some scientific data indicates that physical exercise with customized intensity aimed at increased mobilization of fat reserves has a positive impact on fat oxidation, body composition and insulin resistance [33,34].

Aging is associated with increased oxidative stress, which plays an important role in pathogenesis of many diseases [35,36]. Our observations show that the NW routine with the customized intensity level stimulates the antioxidant protective barrier in women's bodies, which is confirmed by the significant increase in the TAS concentration in plasma. This findings are in line with the results of the previous study which showed that even in a short time (6-week) a properly composed aerobic exercise programme may have beneficial effects of antioxidant defense system for previously sedentary women [37].

In monitoring the antioxidant defenses, the body's nonenzymatic antioxidant network may be assessed through the measurement of the total antioxidant capacity (TAC), defined as the moles of radicals neutralized per 11 of tested sample [38]. The detected increase in the TAS may be explained by the phenomenon of hormesis [39]. According to this theory, the mild oxidative stress, related to regular physical activity, causes adaptive changes in different types of cells and improves their repair and antioxidant systems. Consequently, cells become less prone to oxidative damages [40,41].

In contrast to the increased TAS, the lack of the reduced TOS concentration in this study suggests that reactive oxygen and nitrogen species could have been generated both during the exercise and in the post-exercise period as a result of damage in myocytes. The inflammatory response and the process of phagocytosis in the muscle cells, which have been microdamaged during physical activity, are accompanied by the release of significant amounts of reactive oxygen species, which was described by numerous researchers $[9,10,42]$.

Scientific evidence suggests that senescent organism is more susceptible to oxidative stress generated by exercise due to the structural and biochemical changes promoting release of reactive oxygen species [43]. Significant decrease of uric acid (UA) concentration in serum after a period of trainings found in our study could therefore have been the result of using this compound by working muscles as an antioxidant during subsequent physical efforts. In humans the UA is the end-product of purine metabolism [44] and its increased synthesis is mainly observed during intense physical exercise. It is also known, 
that in the conditions of oxidative stress induced by exercise, muscles may absorb the UA from the bloodstream and use it as one of the antioxidants [45].

Some scientific data indicates a high, positive correlation between the TAS and UA concentration [46]. However, in our study, the increase in the TAS was accompanied by a significant decrease in the concentration of the UA in serum. This reduction in serum uric acid should rather contribute to the decrease in the TAS but the TAS was increased in these participants. Even though uric acid is considered an important antioxidant contributing to the total antioxidant capacity of the plasma, the TAS concentration is also affected by other substances with antioxidant properties, such as ascorbic acid, $\alpha$-tokoferol, albumins, superoxide dismutase and glutathione peroxidase $[47,48]$ which have not been measured in our study. This is why this phenomenon requires further explanation.

It is known now that elevated concentration of the ox-LDL is associated with a higher risk of cardiovascular diseases [49] because the oxidative modification of the LDL particle plays a key role in initiation and development processes of atherogenesis [50]. Although so far, there is skimpy data on the effect of regular physical activity on resting levels of oxidized low-density lipoproteins, the conclusions of some researchers suggest that chronic physical activity may reduce the LDL particle susceptibility to oxidation [51], and lower the concentration of the ox-LDL in blood [52].

With regard to the test results obtained by other authors [52], it seems that the 6-week training period, adopted in our study, was too short to imply a significant reduction in the concentration of the ox-LDL levels in plasma. It should be noted, however, that the average ox-LDL concentration in plasma decreased after training as compared to the baseline, which should be considered a health benefit. Therefore, long-term studies of similar exercise intensity are warranted.

\section{CONCLUSIONS}

Our results demonstrate that even in a short period of 6 weeks, the Nordic walking exercise generates numerous health benefits in an aging body, including the decrease in body fat and improvement of antioxidant defense, while a properly selected intensity seems to boost the effectiveness of such training. Considering that the sample size was relatively small, further larger high-quality studies are warranted to confirm our results. It would also be advisable to examine how under the NW training the concentration of various antioxidants and other markers of oxidative stress in blood changes selectively.

\section{REFERENCES}

1. American College of Sports Medicine, Chodzko-Zajko WJ, Proctor DN, Fiatarone Singh MA, Minson CT, Nigg CR, et al. American College of Sports Medicine position stand. Exercise and physical activity for older adults. Med Sci Sports Exerc. 2009;41:1510-30, https://doi.org/10.1249/MSS. 0b013e3181a0c95c.

2. Hagberg JM. Effect of training on the decline of VO2max with aging. Fed Proc. 1987;46:1830-3.

3. Votruba SB, Horvitz MA, Schoeller DA. The role of exercise in the treatment of obesity. Nutrition. 2000;16(3):179-88, https://doi.org/10.1016/S0899-9007(99)00264-6.

4. Hill JO, Wyatt HR. Role of physical activity in preventing and treating obesity. J Appl Physiol. 2005;99(2):765-70, https:// doi.org/10.1152/japplphysiol.00137.2005.

5. Villareal DT, Apovian CM, Kushner RF, Klein S. Obesity in older adults: Technical review and position statement of the American Society for Nutrition and NAASO, The Obesity Society. Am J Clin Nutr. 2005;82(11):923-34, https://doi.org/ 10.1038/oby.2005.228.

6. Polidori MC, Mecocci P, Cherubini A, Senin U. Physical activity and oxidative stress during aging. Int J Sports Med. 2000;21(3):154-7, https://doi.org/10.1055/s-2000-8881.

7. Fatouros IG, Jamurtas AZ, Villiotou V, Pouliopoulou S, Fotinaksis $\mathrm{P}$, Taxildaris $\mathrm{K}$, et al. Oxidative stress responses in 
older men during endurance training and detraining. Med Sci Sports Exerc. 2004;36(12):2065-72, https://doi.org/10. 1249/01.MSS.0000147632.17450.FF.

8. Karolkiewicz J, Michalak E, Pospieszna B, Deskur-Śmielecka E, Nowak A, Pilaczyńska-Szcześniak $Ł$. Response of oxidative stress markers and antioxidant parameters to an 8-week aerobic physical activity program in healthy, postmenopausal women. Arch Gerontol Geriatr. 2009;49(1): e67-71, https://doi.org/10.1016/j.archger.2008.09.001.

9. Powers SK, Jackson MJ. Exercise-induced oxidative stress: Cellular mechanisms and impact on muscle force production. Physiol Rev. 2008;88:1243-76, https://doi.org/10.1152/ physrev.00031.2007.

10. Gomes EC, Silva AN, de Oliveira MR. Oxidants, antioxidants, and the beneficial roles of exercise-induced production of reactive species. Oxid Med Cell Longev. 2012;2012:756132, https://doi.org/10.1155/2012/756132.

11. Radak Z, Chung HY, Goto S. Exercise and hormesis: Oxidative stress-related adaptation for successful aging. Biogerontology. 2005;6(1):71-5, https://doi.org/10.1007/ s10522-004-7386-7.

12. Church TS, Earnest CP, Morss GM. Field testing of physiological responses assosiated with Nordic Walking. Res Q Exerc Sport. 2002;73(3):296-300, https://doi.org/10.1080/ 02701367.2002.10609023.

13. Hagner W, Hagner-Derengowska M, Wiacek M, Zubrzycki IZ. Changes in level of VO2max, blood lipids, and waist circumference in the response to moderate endurance training as a function of ovarian aging. Menopause. 2009;16(5):1009-13, https://doi.org/10.1097/gme.0b013e31819c0924.

14. Mikalacki M, Rajdo I, Cokorilo N, Korovliev D, Smajic M. Influence of Nordic walking on body composition of elderly women. Health Med. 2012;6(2):476-82.

15. Jasiński R, Socha M, Sitko L, Kubicka K, Woźniewski M, Sobiech KA. Effects of nordic walking and water aerobics training on body composition and the blood flow in lower extremities in elderly woman. J Hum Kinet. 2015;45:113-22, https://doi.org/10.1515/hukin-2015-0012.
16. Figard-Fabre H, Fabre N, Leonardi A, Schena F. Efficacy of Nordic walking in obesity management. Int J Sports Med. 2011;32(6):407-14, https://doi.org/10.1055/s-0030-1268461.

17. Kukkonen-Harjula K, Hiilloskorpi H, Mänttäri A, Pasanen M, Parkkari J, Suni J, et al. Self-guided brisk walking training with or without poles: A randomized-controlled trial in middle-aged women. Scand J Med Sci Sports. 2007; 17:316-23.

18. Song MS, Yoo YK, Choi CH, Kim NC. Effects of Nordic walking on body composition, muscle strength, and lipid profile in elderly women. Asian Nurs Res. 2013;7(1):1-7, https://doi.org/10.1016/j.anr.2012.11.001.

19. Biernat E, Stupnicki R, Gajewski AK. [International Physical Activity Questionnaire (IPAQ) - Polish version]. Wych Fiz Sport. 2007;51:47-54. Polish.

20. Skinner JS, McLellan TM. The transition from aerobic to anaerobic metabolism. Res Q Exerc Sport. 1980;50(1):23448, https://doi.org/10.1080/02701367.1980.10609285.

21. Robergs RA, Roberts SO. Fundamental principles of exercise physiology for fitness, performance, and health. New York: McGraw-Hill; 2002.

22. Kraemer RR, Brown BS. Alterations in plasma-volumecorrected blood components of marathon runners and concomitant relationship to performance. Eur J Appl Physiol Occup Physiol. 1984;55(6):579-84, https://doi.org/10.1007/ BF00423200.

23. Dill DB, Costill DL. Calculation of percentage changes in volumes of blood, plasma and red cells in dehydration. J Appl Physiol. 1974;37(2):247-48.

24. Harrison MH, Graveney MJ, Cohrane LA. Some sources of error in the calculation of relative change in plasma volume. Eur J Appl Physiol Occup Physiol. 1982;50(1):13-21, https:// doi.org/10.1007/bf00952240.

25. Moczko JA, Bręborowicz G. [Not only biostatics]. Poznań: Ośrodek Wydawnictw Naukowych ICB PAN; 2010. p. 10794. Polish.

26. WHO Consultation on Obesity. Obesity: Preventing and managing the global epidemic. Technical report series 
[Internet]. Geneva: The Organization; 1997 [cited 2015 Sept 9]. p. 7-14. Available from: http://catalogue.nla.gov.au/ Record/2483152.

27. Bernas M. [Clinical definition and assessment of obesity]. Terapia. 2005;13:7-9. Polish.

28. Kokot F, Kokot S. [Laboratory tests. Standards and interpretation]. Warszawa: PZWL; 2005. p. 173-74. Polish.

29. Zamboni M, Rossi AP, Fantin F, Zamboni G, Chirumbolo S, Zoico E, et al. Adipose tissue, diet and aging. Mech Ageing Dev. 2014;136-7:129-37, https://doi.org/10.1016/ j.mad.2013.11.008.

30. Achten J, Jeukendrup AE. Optimizing fat oxidation through exercise and diet. Nutrition. 2004;20(7-8):716-27, https:// doi.org/10.1016/j.nut.2004.04.005.

31. Venables CM, Achten J, Jeukendrup AE. Determinants of fat oxidation during exercise in healthy men and women: A cross-sectional study. J Appl Physiol. 2005;98(1):160-7, https://doi.org/10.1152/japplphysiol.00662.2003.

32. Schiffer T, Knicker A, Hoffman U, Harwig B, Hollmann W, Strüder HK. Physiological responses to nordic walking, walking and jogging. Eur J Appl Physiol. 2006;98(1):56-61, https://doi.org/10.1007/s00421-006-0242-5.

33. Dumortier M, Brandou F, Perez-Martin A, Fedou C, Mercier J, Brun JF. Low intensity endurance exercise target for lipid oxidation improves body composition and insulin sensitivity in patients with the metabolic syndrome. Diabetes Metab. 2003;29(5):509-18, https://doi.org/10.1016/S12623636(07)70065-4.

34. Tan S, Wang X, Wang J. Effects of supervised exercise training at the intensity of maximal fat oxidation in overweight young women. J Exerc Sci Fit. 2012;10:64-9, https://doi. org/10.1016/j.jesf.2012.10.002.

35. Ji LL. Oxidative stress and antioxidant defense: Effects of aging and exercise. In: Alessio HM, Hagerman AE, editors. Oxidative stress, exercise and aging. London: Imperial College Press; 2006. p. 85-108.

36. Mezzetti A, Lapenna D, Romano F, Constantini F, Pierdomenico SD, De Cesare D, et al. Systemic oxidative stress and its relationship with age and illness. J Am Geriatr Soc. 1996;44(7):823-37, https://doi.org/10.1111/j.1532-5415.1996. tb03741.x.

37. Leelarungrayub D, Saidee K, Pothongsunun P, Pratanaphon S, YanKai A, Bloomer RJ. Six weeks of aerobic dance exercise improves blood oxidative stress status and increase interleukin-2 in previously sedentary women. J Bodyw Mov Ther. 2011;15(3):355-62, https://doi.org/10.1016/j.jbmt.2010. 03.006.

38. Serafini M, Del Rio D. Understanding the association between dietary antioxidants, redox status and disease: Is the Total Antioxidant Capacity the right tool? Redox Report. 2004;9(3):145-52, https://doi.org/10.1179/1351000042 25004814.

39. Masoro EJ. Hormesis and the antiaging action of dietary restriction. Exp Gerontol. 1998;33(1-2):61-6, https://doi. org/10.1016/S0531-5565(97)00071-5.

40. Finkel T, Holbrook NJ. Oxidants, oxidative stress and the biology of ageing. Nature. 2000;408(6809):239-47, https://doi. org/10.1038/35041687.

41. Radak Z, Taylor AW, Ohno H, Goto S. Adaptation to exercise-induced oxidative stress: From muscle to brain. Exerc Immunol Rev. 2001;7:90-107.

42. Bloomer RJ, Goldfarb AH, Wideman L, McKenzie MJ, Consitt LA. Effects of acute aerobic and anaerobic exercise on blood markers of oxidative stress. J Strength Cond Res. 2005;19(2):276-85, https://doi.org/10.1519/00124278-20050 5000-00007.

43. Ji LL. Exercise at old age: Does it increase or alleviate oxidative stress? Ann NY Acad Sci. 2001;928:236-47, https://doi. org/10.1111/j.1749-6632.2001.tb05653.x.

44. Harrison R. Structure and function of xanthine oxidoreductase: where are we now? Free Radic Biol Med. 2002;33(6):774-97, https://doi.org/10.1016/S0891-5849(02) 00956-5.

45. Hellsten Y, Svensson M, Sjödin B, Smith S, Christensen A, Richter EA, et al. Allantoin formation and urate and glutathione exchange in human muscle during submaximal 
exercise. Free Radic Biol Med. 2001;31(11):1313-22, https:// doi.org/10.1016/S0891-5849(01)00631-1.

46. MacKinnon K, Molnar Z, Lowe D, Watson I, Shearer E. Measures of total free radical activity in critically ill patients. Clin Biochem. 1990;32:263-8, https://doi.org/10.1016/S00099120(98)00109-X.

47. Stocker R, Frei B. Endogenous antioxidant defenses in human blood plasma. In: Sies H, editor. Oxidative stress. Oxidants and antioxidants. London: Academic Press; 1991. p. 213-34.

48. Wayner DD, Burton GW, Ingold KU, Barclay LR, Locke SJ. The relative contributions of vitamin E, urate, ascrobate and proteins to the total peroxyl radical trapping antioxidant activity of human blood plasma. Biochim Biophys Acta. 1987;924(3): 408-19, https://doi.org/10.1016/0304-4165(87)90155-3.

49. Stocker R, Keaney JF. Jr. Role of oxidative modifications in atherosclerosis. Physiol Rev. 2004;84(4):1381-478, https:// doi.org/10.1152/physrev.00047.2003.
50. Holvoet P, Jenny NS, Schreiner PJ, Tracy RP, Jacobs DR. The relationship between oxidized LDL and other cardiovascular risk factors and subclinical CVD in different ethnic groups: The Multi-Ethnic Study of Atherosclerosis (MESA). Atherosclerosis. 2007;194(1):245-52, https://doi. org/10.1016/j.atherosclerosis.2006.08.002.

51. Sánchez-Quesada JL, Ortega H, Payés-Romero A, SerratSerrat J, González-Sastre F, Lasunción MA, et al. LDL from aerobically-trained subjects shows higher resistance to oxidative modification than LDL from sedentary subjects. Atherosclerosis. 1997;132(2):207-13, https://doi.org/10.1016/S00 21-9150(97)00108-1.

52. Vasankari TJ, Kujala UM, Vasankari TM, Ahotupa M. Reduced oxidized LDL levels after a 10-month exercise program. Med Sci Sports Exerc. 1998;30(10):1496-501, https:// doi.org/10.1097/00005768-199810000-00005.

This work is available in Open Access model and licensed under a Creative Commons Attribution-NonCommercial 3.0 Poland License - http://creativecommons.org/ licenses/by-nc/3.0/pl/deed.en. 